\title{
Model system development and uncertainty for the provisionary management of extreme floods in large river basins
}

\author{
K.-E. Lindenschmidt ${ }^{1}$, K. Fleischbein ${ }^{1}$, T. Petrow ${ }^{1}$, S. Vorogushyn ${ }^{1}$, S. Theobald ${ }^{2}$, and B. Merz ${ }^{1}$ \\ ${ }^{1}$ GFZ GeoForschungsZentrum Potsdam, Section 5.4 - Engineering Hydrology, Telegrafenberg, 14473 Potsdam, Germany \\ ${ }^{2}$ Institute of Water Resources Management, Hydraulic and Rural Engineering, University of Karlsruhe (TH), Kaiserstraße 12, \\ 76128 Karlsruhe, Germany
}

Received: 7 January 2005 - Revised: 1 August 2005 - Accepted: 1 September 2005 - Published: 16 December 2005

\begin{abstract}
A research project is introduced in which a modelling system is being developed to quantify risks of extreme flooding in large river basins. In the system, computer models and modules are coupled to simulate the functional chain: hydrology - hydraulics - polder diversion - dyke failure flooding - damage estimate - risk assessment. In order to reduce uncertainty in flood frequency analyses, data sets are complimented with information from historical chronicles and artwork. Probable maximum precipitation and discharge are calculated to indicate upper bounds of meteorological and hydrological extremes. Uncertainty analysis is investigated for different degrees of model complexity and compared at different basin scales.
\end{abstract}

\section{Introduction}

Worldwide there is a continuous increase in damages caused by extreme natural events. In part this is due to the fact that human society is becoming increasingly vulnerable to the effects of these events (Munich Re Group, 2005). In addition, it is presumed that climatic change will intensify and increase the magnitude and frequency of climate-dependent catastrophic events. Apart from naturally occurring extremes, anthropogenic developments are also increasing the potential for damages (e.g. riverside settlements).

Due to the flood damages in August 2002 in the Elbe river basin in Germany and the Czech Republic public awareness for the improvement of the provision and management of such emergencies has risen. This gave impetus to establish a junior research team at GeoForschungsZentrum in Potsdam in cooperation with the University of Karlsruhe (within the network CEDIM - Center for Disaster Management and Risk Reduction Technology) dedicated to research of extreme flood events in large river basins.
The visionary goal to be reached at the completion of the research is:

- Development of a modelling system allowing the implementation and interchangeability of hydrological and hydraulic processes of varying degrees of complexity...

- ... for the provisionary management of extreme flood events in large river basins...

- ... using a computer-automated methodology that is easily and flexibly transferable to basins of different (macro)scales.

A modelling system is required which couples all necessary models and modules together into one integrated system, to ensure that the most important components of the hydrological cycle causing extreme floods are included in the simulations. The main components include precipitation, runoff generation and routing. The latter can be greatly affected by polder diversions and dike breaches. Hence, their impact must be incorporated.

An important question in developing such a modelling system is how complex should the description of the hydrological and hydraulic processes be in order to retain both good accuracy and high predictive power in the system's state variables. More complexity may lead to higher accuracy since more processes are represented to reflect reality. Using models for risk assessment Cox (1999) shows that greater complexity leads to more certainty in risk estimates but also states that the additional complexity included in the model must allow additional relevant observations to be incorporated. The downside is that such complex systems become over-parameterised (or overly sensitive as stated by Snowling and Kramer, 2001) making validations and predictions of other flood events difficult. Hence, an aim of the project is to answer the question: 

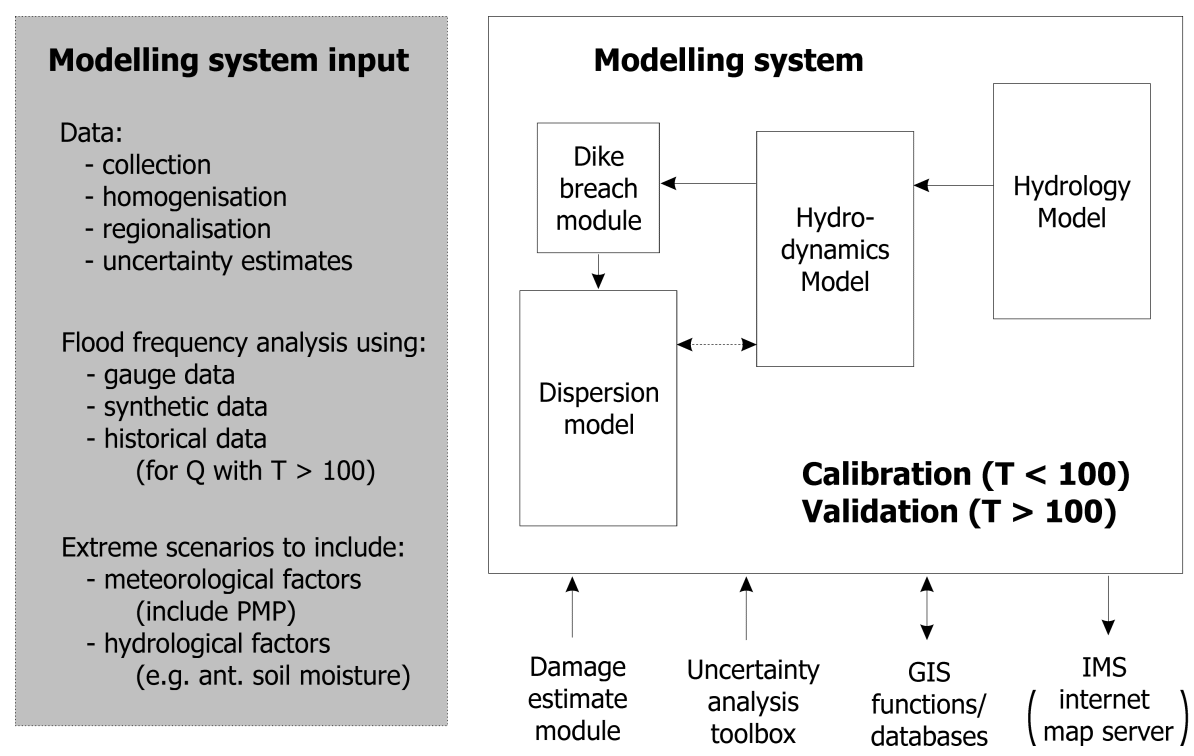

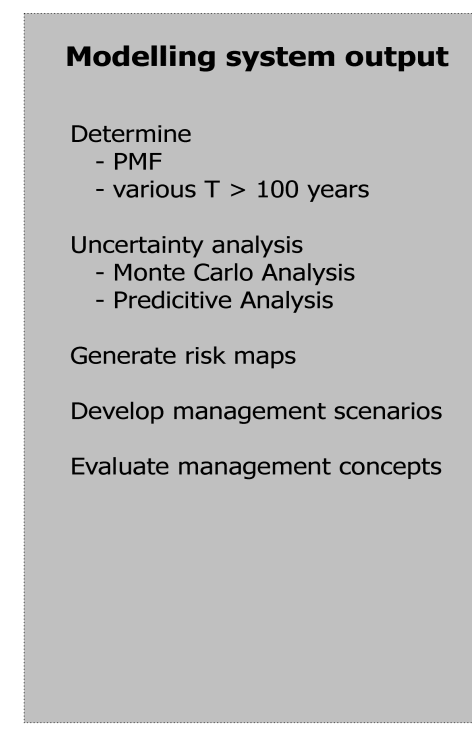

Fig. 1. Concept for the research project.

How complex must the modelling system be to ensure good accuracy and predictability of the simulation results?

Lindenschmidt et al. (accepted) found that the relationship of accuracy and predictive ability with model complexity may also change at different scales. Models of smaller scale require a more detailed description of the processes to accurately simulate the state of the modelled area for a given time frame. Sivapalan (2003) mentions that increased complexity is required to capture the hydrological response at the hillslope scale compared to the catchment scale. For example, Butts et al. (2004) and Perrin et al. (2001) found that hydrological variables modelled for large river basins were more accurately simulated using simpler process descriptions. van der Linden and Woo (2003), who applied models with increasing complexity to simulate hydrological conditions in subarctic catchments, also found that with decreasing temporal and spatial scale, process representation needs to be more complex. Hence, an additional question that will be pursued in this research project is:

How does the complexity - uncertainty relationship of the modelling exercise change when the modelling system is applied to different macro-scales (e.g. Elbe basin and Mulde subbasin)?

An important prerequisite for developing provisionary management concepts for the mitigation of extreme flood events is to identify areas of potentially high risk to such events. Risk maps are extremely useful, however methodologies for very large river basins are still rare. Kron and Willems (2002) identify eight independent regional loss accumulation zones in Germany in which probable maximum losses are calculated for five different flood scenarios corresponding to return periods ranging from 10 to 200 years. Zoning is carried out, not of rivers alone, but of entire large catchment areas. Similar efforts for Germany have been carried out by Kleeberg (2001), who concentrated the zoning to the flood regions along rivers and who implemented the method in the software package ZÜRS (Zoning System for Floods, Backwater and Heavy Rains). Rodda and Berger (2002) established differentiated risk zones in the flooded areas near the river itself, and Hall et al. (2003) and Sayers et al. (2002) have extended this approach to include the probabilities of dike failures. The implementation of dike fragility curves has also found application in the USA (USACE, 1996, 1999). These methods provide a rough orientation of where "hot spots" occur in terms of flood risk on very large (nationwide) scales. These have their justification for high-level strategic planning for entire countries and provide information on a scale that is valuable for re-insurance companies, which base their policies on probable maximum loss estimates. The downside of these methods is that the spatial resolution is generally too coarse and the results not differentiated enough to be applicable for the development of mitigation concepts. Hence, an additional aim of this project is to investigate:

How much explanatory power is forgone in making reasonable risk assessments for the development of provisionary management concepts when applying the modelling system methodology to larger scales? How can explanatory power be improved for the largest basins?

\section{Methodology}

The concept of the research project is illustrated in Fig. 1. An aim of the project is to develop a modelling system whose 


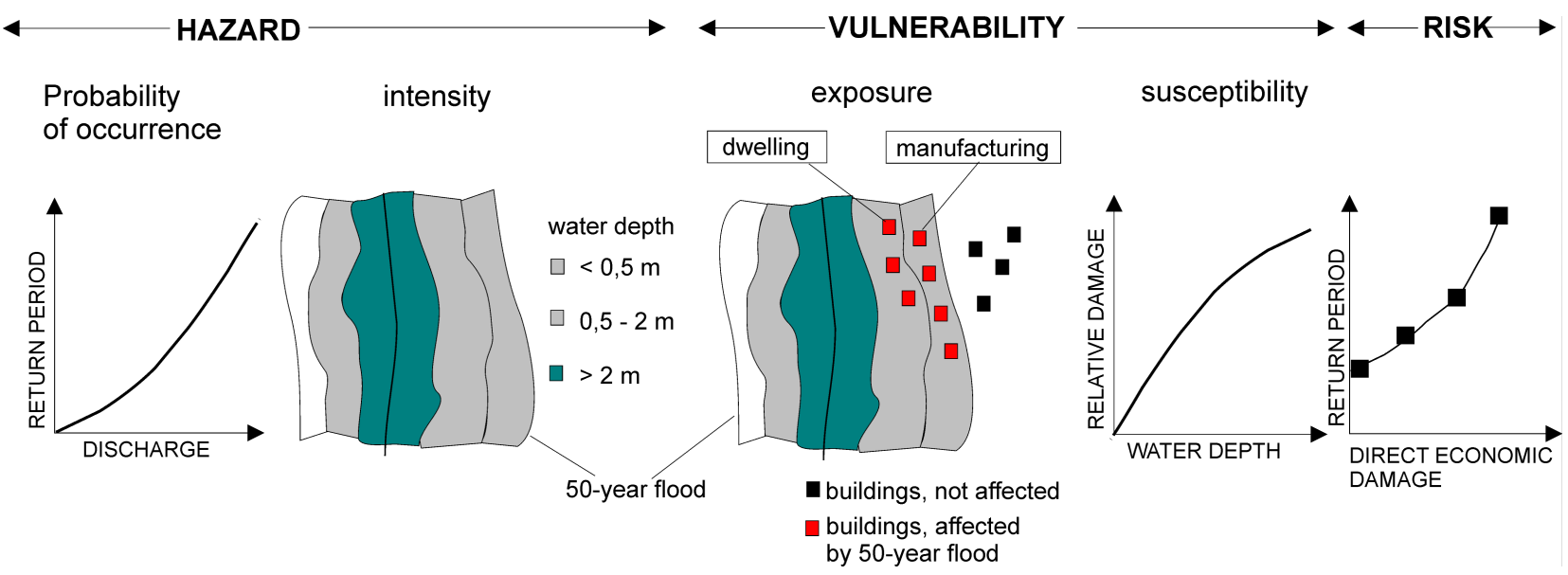

Fig. 2. Flood risk as interaction of hazard and vulnerability (sensu Merz and Thieken, 2004).

core consists of the coupling of four models. The runoff generation components describe the precipitation and snowmelt runoff on the land surfaces. As flooding events become more extreme hydrograph routing of the generated runoff becomes increasingly important, especially in the lowland river reaches (hydrodynamic module). A unique feature of this modelling system is the incorporation of a dike breach module. This component calculates the probability of a dike failure depending on the condition and type of dike and on the hydraulic variables in the river, such as water level and water velocity in the main channel. In the event of a dike breach a dispersion model is executed to simulate the movement of water from the breach area into the hinterland. This model may also be used to simulate the movement of water through a polder system. Since the dispersed water also affects the hydraulics in the river, there is an interactive linkage between the dispersion and routing components.

Other components may be implemented into the system such as a damage estimator module and an uncertainty analysis toolbox. Databases and a library of GIS (Geographical Information System) functions are accessible by the system and results are displayed using an IMS (Internet Map Server).

Data is required as input to run the modelling system, which needs to be collected, homogenised and regionalised from point samples to area descriptions. Estimates of the statistical uncertainty in the data and parameter values are required for an uncertainty analysis. The modelling system can then be calibrated globally with reasonable "certainty" for events with return periods less than 100 years. Data sets longer than one century are rare and uncertainty increases when extrapolating the discharges for return periods of 250 or 500 years from these data sets. To gain more certainty and to narrow confidence intervals the interpolated values are to be complimented with historical data. Chronicles may provide insight on discharge and precipitation. Artworks may additionally provide estimates of water levels at certain locations for corresponding discharges from documented meteorological conditions. Weather generators may (time per- mitting) also be used to produce synthetic data to fill data gaps in time series and to imitate extreme weather conditions by superimposing extreme meteorological variables. These data will also provide a data set that can be used for the validation of the modelling system for extreme flooding events ( $T>100$ years).

Superimposing the extreme values of meteorological variables also serves as a basis for the calculation of the probable maximum precipitation (PMP) of a subbasin. Together with extreme hydrological factors such as very high antecedent soil moistures the probable maximum flood (PMF) can be simulated. This will set the upper limit of flooding possible in the basin.

Once the modelling system has been set up a Monte Carlo Analysis (MOCA) can then be carried out to determine probability distributions of hydrological output variables, such as discharges and water levels, for certain return periods. These output distributions are obtained when parameters and input data of the modelling system are varied according to specific probability distributions within their uncertainty limits. Only those parameters and data will be used for the MOCA which are most sensitive to the output variables. This is determined by running a sensitivity analysis (SENA) of the system.

The probability of occurrence calculated from the MOCA together with the intensity of the event (return period) establishes the hazard induced by the flood event (see Fig. 2). Using land-use information and damage costs as functions of water depth and perhaps other factors (i.e. flow velocities) the vulnerability of certain land-use types that are exposed to the flood and their susceptibility to damage by the flooding can be assessed. Both hazard and vulnerability are combined to calculate risk and can be used to establish risk maps. Once areas of exceptionally high risk ("hot spots") have been identified scenarios can be run to test various management concepts for flood mitigation. 


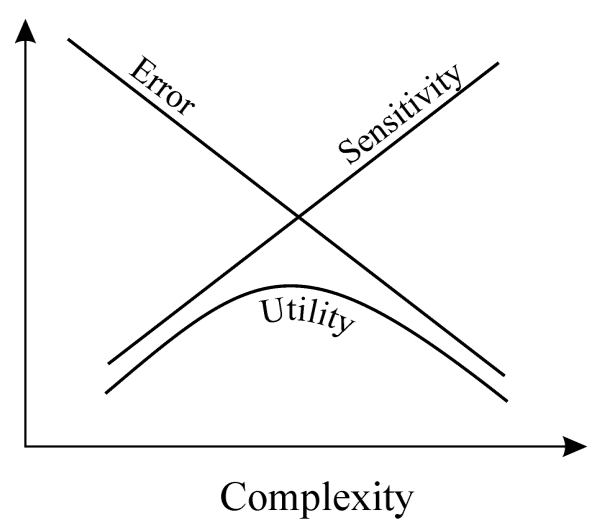

Fig. 3. Complexity versus the uncertainty components, sensitivity and error (adapted from Snowling and Kramer (2001) and Lindenschmidt et al. (accepted)).

\section{Model complexity and uncertainty}

One aspect of the project is to model the numerous hydrological and hydraulic processes with varying degrees of complexity. The aim is to determine how complex a model setup must be in order to obtain the required accuracy of the results (how well do simulations and data coincide).

Table 1 shows various methods corresponding to the simulation of selected components of the hydrological cycle with different complexity levels. Several complexity mixes can also be tested for accuracy by combining processes of different complexity from each hydrological component. The discretization of the catchment area can also be carried out with varying degrees of resolution (see Table 2). This may range from a very coarse (low complexity) to a very fine (high complexity) discretization:

- lumped parameters for each subbasin, an approach found for example in the HEC-1 model (HEC, 1998);

- landscape units in which discretized units are derived from lateral flow characteristics in the surface areas (Güntner and Bronstert, 2004);

- hydrological response units in which units are discretized according to related geomorphologic characteristics (Flügel, 1995);

- grid cells, as used for example in the WaSiM-ETH model (Schulla, 1997).

Snowling and Kramer (2001) proposed a hypothesis in which model sensitivity and error, which constitutes model uncertainty, is related to the model's complexity level (see Fig. 3). "Model sensitivity increases with model complexity due to the larger number of degrees of freedom and the structure of the interactions between parameters and state variables. Modelling error decreases with increasing model complexity as the more complex models are able to better simulate reality with more processes included and fewer simplifying assumptions" (Snowling and Kramer, 2001, p. 21). "Increased

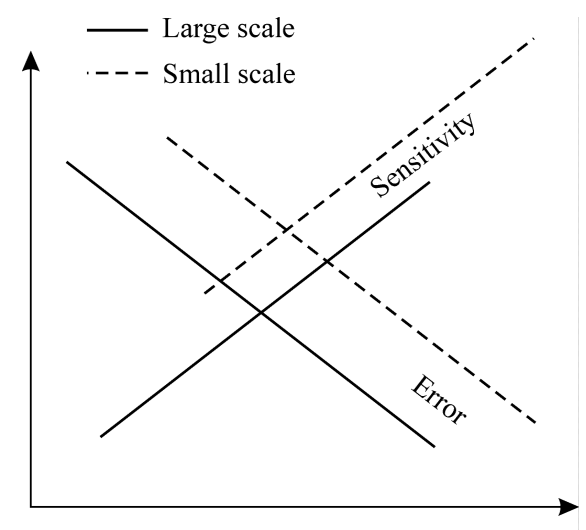

Complexity

Fig. 4. The complexity vs. uncertainty relation shifts at different scales, as proposed by Lindenschmidt et al. (accepted).

complexity means that more processes will be represented in the system potentially reducing the model error (deviations between measurement samples and simulation results). The downside is that increasing the model complexity increases the number of degrees of freedom within the model (more parameters and variables) which can be expressed as the total increase in model sensitivity (the change in output results due to a percentage change in input data such as parameter settings and initial and boundary conditions). Over-parameterization makes calibration more difficult and reduces the predictive power of the model (if the model essentially needs to be re-calibrated for any slight changes in the initial and boundary conditions it has lost its capability as a predictive tool)" (Lindenschmidt, accepted).

Snowling and Kramer (2001) confirmed their hypothesis on a sorption model for radioactive zinc onto sediments in solution (LeBeuf, 1992; cited in Snowling and Kramer, 2001). In a second model in which the transport of a groundwater tracer plume was simulated, sensitivity does increase with increasing complexity but no relation was evident between error and complexity. The hypothesis has also been tested and confirmed using a water quality model developed for the Saale river (Lindenschmidt, submitted) and a lock-and-weir system on the same river (Lindenschmidt et al., accepted).

Ideally, the best model is one in which both sensitivity and error are minimised. Here, a utility function may be implemented to evaluate which complexity is best suited for the characteristics of the study site.

A second hypothesis has been proposed by Lindenschmidt et al. (accepted) stating that there will be a shift in the error and sensitivity curves when implementing the same model for studies of different scale (see Fig. 4). For example, when reducing both the temporal and spatial scales, processes become more dynamic and quick-lived (Blöschl and Sivapalan, 1995) and increased model complexity is required to obtain the same reduction in model error. Additional processes which may be dampened or have less impact at the large scale need now to be included in the small-scale model description 
Table 1. Processes of different complexity levels.

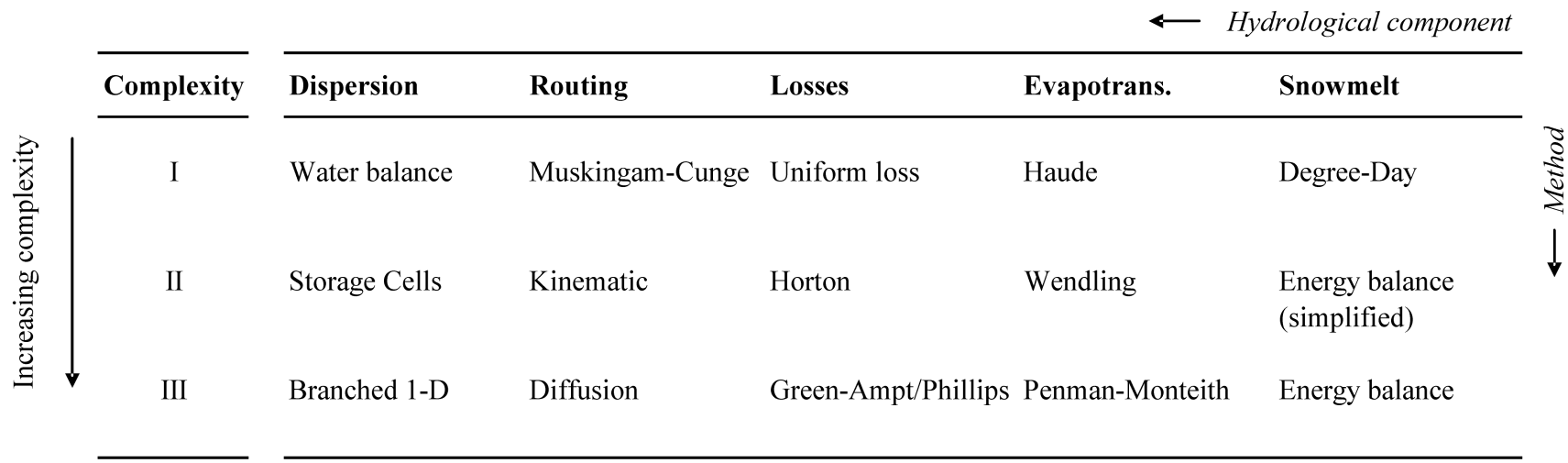

Table 2. Complexity levels of different discretization schemes.

\begin{tabular}{|c|c|}
\hline Complexity & Discretization \\
\hline I & $\begin{array}{l}\text { Sub-basins } \\
\text { (lumped) }\end{array}$ \\
\hline II & $\begin{array}{l}\text { Landscape Units (LU) } \\
\text { (different \# of layers) }\end{array}$ \\
\hline III & $\begin{array}{l}\text { Hydrological Response Units (HRU) } \\
\text { (different \# of layers) }\end{array}$ \\
\hline IV & $\begin{array}{l}\text { Grid Cells } \\
\text { (different resolution) }\end{array}$ \\
\hline
\end{tabular}

to achieve better accuracy in model output. This increase in complexity also increases the overall model sensitivity since the inclusion of additional processes brings with it additional parameters and data input.

\section{Conclusions}

- The modelling system provides additional capabilities for uncertainty analysis such as "cross-model" error propagation in model chains and error dampening/amplifying in model interaction and feedbacks.

- The provision of risk maps by the modelling system is a firm basis to establish concepts for the provisionary management of extreme flood events.

- The two proposed hypotheses, the model complexity vs. uncertainty relationship and its shift at different scales, provide a framework in which to combine and present the results of the modelling system.

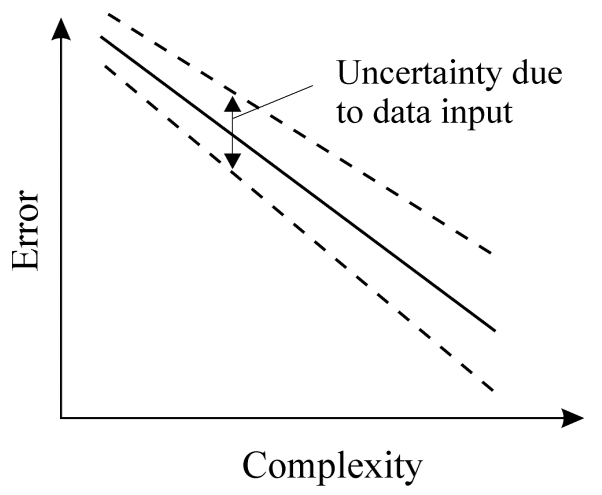

Fig. 5. The effect of input data uncertainty on error versus complexity.

\section{Outlook}

An interesting aspect for future work is to incorporate input data uncertainty into the Snowling and Kramer hypothesis. Figure 5 suggests that the error versus complexity curve fluctuates within an error band if the uncertainty due to sampling error is considered. Usually more data is required for setting up models or greater complexity causing the band to widen.

Co-operations with meteorologists and climatologists are currently being pursued in order to couple a regional climate model with our hydrological modelling system. This will allow a stochastic component of the meteorological input data to be embedded in the hydrological modelling and enable long-term scenarios with the influence of climate change to be simulated.

Edited by: P. Krause, K. Bongartz, and W.-A. Flügel

Reviewed by: anonymous referees 


\section{References}

Blöschl, G. and Sivapalan, M.: Scale issues in hydrological modeling: a review, Hydrological Processes, 9, 251-290, 1995.

Butts, M. B., Payene, J. T., Kristensen, M., and Madsen, H.: An evaluation of the impact of model structure on hydrological modelling uncertainty for streamflow simulation, J. Hydrol., 298, 242-266, 2004.

Cox Jr., L. A.: Internal dose, uncertainty analysis and complexity of risk models, Environmental International, 25(6-7), 841-852, 1999.

Flügel, W.-A.: Delineating hydrological response units by geographical information system analysis for regional hydrological modelling using PRMS/MMS in the drainage basin of the river Bröl, Germany, Hydrological Processes, 9(3-4), 423-436, 1995.

Güntner, A. and Bronstert, A.: Representation of landscape variability and lateral redistribution processes for large-scale hydrological modelling in semi-arid areas, J. Hydrol., 297, 136-161, 2004.

Hall, J. W., Dawson, R. J., Sayers, P. B., Rosu, C., Chatterton, J. B., and Deakin, R.: A methodology for nation-scale flood risk assessment, Water and Maritime Engineering, 156(WM3), 235247, 2003.

HEC: HEC-1 flood hydrograph package, user's manual (version 4.1), Hydrologic Engineering Center, US Army Corps of Engineers, Davis, CA, 1998.

Kleeberg, H.-B.: Zur Hochwasser-Risikozonierung der deutschen Versicherungwirtschaft, in: Hochwasser - Niedrigwasser Risiken, Nürnberger Wasserwirtschaftstage des ATV-DVWK Landesverbandes Bayern, 9-10 May 2001, pp. 39-50, 2001.

Kron, W. and Willems, W.: Flood risk zoning and loss accumulation analysis for Germany, International Conference on Flood Estimation, 6-8 March 2002, Berne, Switzerland, pp. 549-558, 2002.

LeBeuf, M.: Kinetics of trace metal interactions with lake sediments, Ph.D. thesis, McMaster University, Hamilton, Ontario, Canada, 1992.

Lindenschmidt, K.-E.: The effect of complexity on parameter sensitivity and model uncertainty in river water quality modelling, Ecological Modelling, accepted, 2005.

Lindenschmidt, K.-E., Wodrich, R. and Hesse, C.: The effects of scaling and model complexity in simulating the transport of inorganic micro-pollutants in a lowland river reach, Water Quality Research Journal of Canada, accepted, 2005.
Merz, B. and Thieken, A. H. Flood risk analysis: concepts and challenges, Österreichische Wasser- und Abfallwirtschaft, 56(3-4), 27-34, 2004.

Munich Re Group: Topics Geo - Annual review: natural catastrophes 2004, Publication No. 302-04321, http://www.munichre. com/publications/302-04321_en.pdf?rdm=66495, 2005.

Perrin, C., Michel, C., and Andréassian, V.: Does a large number of parameters enhance model performance? Comparative assessment of common catchment model structure on 429 catchments, J. Hydrol., 242, 275-301, 2001.

Rodda, H. and Berger, A.: The application of flood modelling and mapping for managing flood risk in the UK. International Conference on Flood Estimation, 6-8 March 2002, Berne, Switzerland, pp. 645-650, 2002.

Sayers, P., Hall, J., Dawson, R., Rosu, C., Chatterton, J., and Deakin, R.: Risk assessment of flood and coastal defences for strategic planning (RASP) - a high level methodology, DEFRA Conference of Coastal and River Engineering, Keele University, July 2002.

Schulla, J.: Hydrologische Modellierung von Fließgebieten zur Abschätzung der Folgen von Klimaänderungen, Ph.D. thesis, ETH 12018, Verlag Geographisches Institut ETH, Zurich, 1997.

Sivapalan, M.: Process complexity at hillslope scale, process simplicity at the watershed scale: is there a connection? Hydrological Processes, 17, 1037-1041, 2003.

Snowling, S. D. and Kramer, J. R.: Evaluating modelling uncertainty for model selection, Ecological Modelling, 138(1), 17-30, 2001.

USACE: Engineering and design - risk-based analysis for flood damage reduction studies, Pub. \# EM1110-2-1619, US Army Corps of Engineers, Washington, DC 203141000, http://www.usace.army.mil/inet/usace-docs/eng-manuals/ em1110-2-1619/toc.html, 1996.

USACE: Risk-based analysis in geotechnical engineering for support of planning studies, Pub. \# ETL 1110-2-556, US Army Corps of Engineers, Washington, DC 203141000, http://www.usace.army.mil/inet/usace-docs/eng-tech-ltrs/ etl1110-2-556/toc.html, 1999.

van der Linden, S. and Woo, M.: Application of hydrological models with increasing complexity to subarctic catchments, J. Hydrol., 270, 145-157, 2003. 